\title{
Correlation between Head Computed Tomography Scan Examination and Cranial Index Measurement in Pediatric Hydrocephalus
}

\author{
Nony Zulfariska ${ }^{1 *}$, Pande Putu Yuli Anandasari ${ }^{1}$, Ni Nyoman Margiani ${ }^{1}$, Firman Parulian \\ Sitanggang ${ }^{1}$, Putu Patriawan ${ }^{1}$, I Gde Raka Widiana ${ }^{2}$ \\ ${ }_{1}^{1}$ Departement of Radiology, Faculty of Medicine, Universitas Udayana, Denpasar, Bali, Indonesia \\ 2 Departement of Internal Medicine, Faculty of Medicine, Universitas Udayana, Denpasar, Bali, Indonesia
}

\begin{abstract}
DATE OF ARTICLE:
Received: 03 Aug 2021

Reviewed: 29 Nov 2021

Revised: 01 Jan 2022

Accepted: 04 Jan 2022

CORRESPONDENCE:

nonyzulfariska@yahoo.com

DOI:

10.18196/mmjkk.v21i2.12464

TYPE OF ARTICLE:

Research

Abstract: Hydrocephalus in children can inhibit child growth. However, if treated immediately, the patient will develop normal intelligence. In radiology, the most important problem is to detect hydrocephalus early. Currently, radiology examinations can detect hydrocephalus accurately with a CT scan to identify the presence of blockages and assess the degree. Skull radiography is used to assess the presence of advanced hydrocephalus. A comparison is carried out and assesses the relationship between hydrocephalus measurement on the ventricular and cranial index by scanogram. The study used a cross-sectional analytics design, using Picture Archiving and Communication System (PACS) data. There were 68 samples taken using consecutive sampling, obtaining ventricular index measurement results above 0.30 , and patients under 12 years old. Spearman rank test showed a correlation between the ventricular index measurements and cranial index, with Spearman's Rho $(r)=0.856$ and $p<0.001$ with linear equation $Y=2.973+0.005 X$. It revealed that the constant 2.973 indicated that if there is no B coefficient value, the participation value will be 2.973. Furthermore, regression coefficient $\mathrm{X}$ of 0.005 indicated that the participation value grows by 0.005 for every 1 addition of the $\mathrm{B}$ coefficient value with $\mathrm{R}^{2}=0.340$.
\end{abstract}

Keywords: Pediatrics Hydrocephalus; Ventricular Index; Cranial Index

\section{INTRODUCTION}

Children are the next generation of the nation. The strong or fragile beginning of a country can be seen from the quality of the next generation; if children are born with a low level of health, the nation's condition is likely to become weak and unable to build the country optimally. ${ }^{1}$ The phenomenon of pediatric health in Indonesia becomes an interesting aspect of identifying as the child is still in development and needs more attention from parents and caregivers. If the child's health is impaired, his development can also become stunted, one of which can be caused by hydrocephalus.

Hydrocephalus is a dynamic process caused by the build-up of cerebrospinal fluid (CSF) inside the head that causes the dilation of the ventricle cerebri and puts pressure on the brain. ${ }^{2}$ Hydrocephalus occurs when a blockage prevents CSF from draining, the brain does not absorb enough CSF, and the brain produces too much CSF. Meanwhile, ventriculomegaly occurs when the brain's ventricles (fluid-filled space) are larger than normal size without pressure on the brain. Ventriculomegaly occurs when there is too much CSF; the baby has idiopathic intraventricular hemorrhage, ischemia, and the brain has not formed normally. In diagnosing hydrocephalus, CT-Scan is the preferred tool over other imagings for neurosurgeons, namely, to determine when to install a ventricular shunt. Therefore, determining the degree of mild or severe hydrocephalus is very important. The number of hydrocephalus cases in the world is quite high. In the Americas, the incidence rate of hydrocephalus reaches $0.5-4$ per 100 births, while Indonesia reaches 10 per mile per year. ${ }^{3}$ 
Assessment of ventricular size is important in the clinical management of hydrocephalus and neurological disorders for neurosurgery. Evans, in 1982 introduced a method of measurement with a "ventricular size index" index system that other researchers had recognized as a way of determining the degree of hydrocephalus that could later be evaluated after the installation of ventriculoperitoneal shunt. In this case, anteroposterior and lateral skull radiography are expected to be used in addition to detecting early symptoms of hydrocephalus. It can also be used for post-installation evaluation of the area's ventriculoperitoneal shunt (VP Shunt). ${ }^{4}$ Therefore, the author attempts to start the initial step by comparing and connecting (correlation) between hydrocephalus measurement, with CT examination and head measurement with scanogram also from CT-Scan which has been converted into size such as in skull radiography.

\section{MATERIALS AND METHOD}

Using a latitude cut design, this study was conducted at RSUP Sanglah Denpasar in March 2020 January 2021. The research population included all hydrocephalus patients aged 0-12 years who come through the emergency installation (IRD), polyclinic, and hospitalization at RSUP Sanglah. After the screening based on inclusion (all pediatric patients who have been diagnosed with hydrocephalus and perform a CT Scan at Sanglah Hospital and patients under 12 years old) and exclusion criteria (CT scan images that are not readable such as moving or incomplete images, pediatric patients with holoprosencephaly, arachnoid cyst, cavum septum pellucidum and hydranencephaly), 68 samples were selected. The dependent variable was the cranial index based on the scanogram, and the independent variable was the ventricular index measurement on the Head CT Scan with minimum sample size calculated by sample size for test relationship between 2 variables.

$$
n=\left[\frac{Z \alpha+Z \beta}{0.5 \ln \left[\frac{(1+r)}{(1-r)}\right]}\right]^{2}+3
$$

Information:

$\mathrm{n}=$ number of samples

$Z a=$ alpha standard deviation. Type I error of $5 \% Z a=1.96$

$Z \beta=$ beta standard deviation. Type II error of $20 \% Z \beta=0.842$

$r=$ assumed correlation coefficient of 0.3

Based on the calculation above, the minimum number of samples used in this study was 60 samples of hydrocephalus. The sample size with drop-out correction was 66 samples. Primary data collection was conducted through consecutive sampling.

The tool used in this study was the Picture Archiving and Communication System (PACS) at RSUP Sanglah to identify the results of Head CT- Scan by Philips Brilliance 32 with a slice thickness $1-0.5 \mathrm{~mm}$, performed with coronal reformats axial, sagittal, and data collection sheet, covering the number, initials of the patient, ventricular and cranial index measurement. The images obtained from this eligible sample were evaluated separately and blind by two radiologists who have experienced $>5$ years of consultant pediatric radiologists. As this research used data in the form of a variable scale, the Bland Altman plot for interobserver agreement analysis was used.

Research Stage sampling pictures were in a row sampling through a set of computers connected through the PACS in the reading room of radiology RSUP Sanglah Denpasar, and then Statistical decisions were made by PACS with the condition of the time registered in January 2018 to December 2020. Inclusion criteria were filtered by the CT Scan result of patients with hydrocephalus less than 12 years. It also conducted screening of research figures according to exclusion criteria, i.e., patients picture with incomplete CT-Scan or with not optimal and patients diagnosed with Holoprosencephaly, Hydranencephaly, Cyst Arachnoid, and Cav Septum Pellucidum. The patient data that has been collected was included in a special folder of "research," and then sampling was performed until the minimum number of samples was fulfilled.

The determination of Ventricular Index ( $\mathrm{VI})$ was conducted with the formula of comparison of the widest diameter of the anterior cornu ventricular lateral $(A)$ and with the bifrontal transverse diameter at the same level (B). If the resulting number exceeded 0.30 , the patient was considered hydrocephalus and entered the inclusion criteria. ${ }^{5}$ 


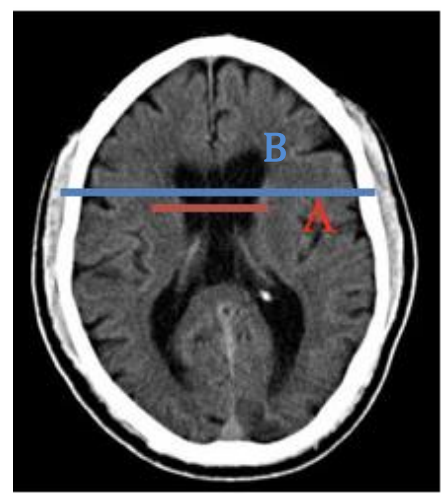

Figure 1: Ventricular index measurement on head CT Scan, Aline (red) representative cornu anterior lateral ventricle, and $B$ line (blue) representative diameter bifrontal at the same level

Measurements were also carried out on the cranial index $(\mathrm{Cl})$ based on the scanogram by comparing the transverse diameter of biparietal (BP) and the length of fronto-occipital diameter line (FO) then multiplied by $100 .^{6}$
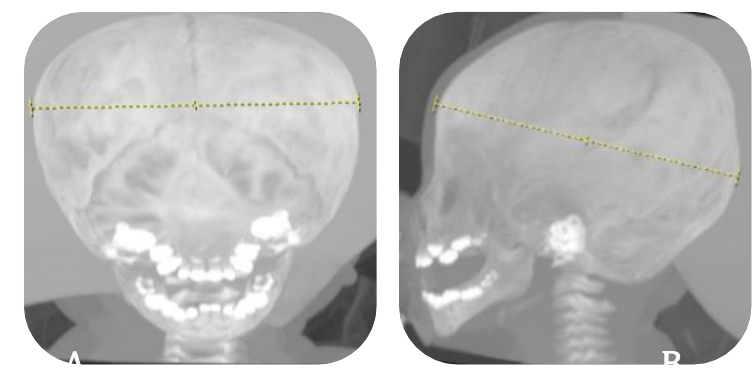

Figure 2: Cranial index measurement on scanogram (A) Representative transverse diameter of biparietal line and (B)

Representative fronto-occipital diameter line

The description of the CT-Scan radiography to be evaluated had been eliminated, and the results of the reading evaluation were collected and assessed accordingly (agreement), independently, and blindly. Research data was recorded on the prepared data collection sheet and later edited. The coding entry and cleaning were done by statistical processing of data using computer programs (SPSS and STAT)

This study's data analysis techniques consisted of descriptive statistical analysis to describe the characteristics of subjects and research variables. The results of this descriptive analysis were described in the form of a single distribution table. The suitability of ventricular index (VI) measurement results on CTScan and cranial index $(\mathrm{Cl})$ measurements on scanogram by the first and second observer were equalized. The data normalization analysis was then conducted with Kolmogorov-Smirnov.

The relationship analysis (correlation) aims to assess the relationship between ventricular index (VI) measurements on CT-Scan and cranial Index $(\mathrm{Cl})$ measurements on scanograms using Pearson or Spearman correlations. This analysis determines the direction of the relationship between independent and dependent variables and predicts whether the value of independent variables increases or decreases. It was also tested with the level of significance determined by the value of $\mathrm{P}<0.05$ and $\mathrm{Cl} 95 \%$.

\section{RESULTS}

Characteristics of research samples and descriptive observation of CT Scans during the data collection period from January 2018 to December 2020 indicated 68 research subjects were obtained. Characteristics of subject distribution in hydrocephalus patients aged 0-12 years are shown in Table 1. It shows based on age; gender; degree of hydrocephalus (was classified into three grades [mild, moderate and severe] determined using the ventricular/biparietal [V/BP] ratio from the axial $\mathrm{CT}$ scan at the midportion of the bodies of the lateral ventricles, showing the greatest ventricular dilatation); type of hydrocephalus (the two major types of hydrocephalus are called communicating hydrocephalus, occurs when the flow of CSF is blocked after it exits the ventricles. The CSF can still flow between the ventricles, the passages between which remain open; reduced flow and absorption of CSF into specialized blood vessels called arachnoid villi can also result in a build-up of CSF in the ventricles. The other type is noncommunicating hydrocephalus happening when the flow of CSF is blocked along with one or more of the 
narrow passages connecting the ventricles); and causes hydrocephalus (some cases are present at birth, while others develop in childhood or adulthood. Hydrocephalus can be inherited genetically. It may be associated with developmental disorders, like spina bifida or encephalocele, brain tumors, head injuries, hemorrhage, or diseases such as meningitis).

Table 1. Characteristics of research samples

\begin{tabular}{lc}
\hline Characteristics & $\mathbf{n}(\%)$ \\
\hline Gender & $35(51.47 \%)$ \\
Male & $33(48.53 \%)$ \\
Female & $18(26.47 \%)$ \\
Hydrocephalus Grade & $21(30.88 \%)$ \\
Mild & $29(42.65 \%)$ \\
Moderate & \\
Severe & $48(70.59 \%)$ \\
Hydrocephalus Type & $20(29.41 \%)$ \\
Communicating & \\
Non-Communicating & $44(64.71 \%)$ \\
Hydrocephalus Etiology & $11(16.18 \%)$ \\
Congenital & $6(8.82 \%)$ \\
Infection & $7(1029 \%)$ \\
Tumor & \\
Others &
\end{tabular}

The median (IQR) age of the 68 research samples in this study was nine months, with the youngest research subject aged o months and the oldest age of the sample 120 months. There were 35 samples (51.47 $\%)$ from the male gender and 33 samples from the female gender ( $48.53 \%$ ). Severe hydrocephalus (V/BP ratio $>0.61$ ) cases accounted for 29 samples $(42.65 \%$ ), moderate hydrocephalus (V/BP ratio 0.41-0.60) cases accounted for 21 samples (30.88\%), and mild hydrocephalus (V/BP ratio 0.26-0.40) accounted for 18 samples (26.47\%). The communicating type had the most patients with hydrocephalus of 48 samples (70.59\%), while the non-communicating type had 20 samples (70.95\%). Congenital abnormalities were the first cause of hydrocephalus in children in 44 samples, according to the data on the causes of hydrocephalus $(64.71 \%)$. Furthermore, it came infection, which accounted for 11 samples (16.18\%), tumor cause, which accounted for 6 samples ( $8.82 \%$ ), and other unknown causes, which accounted for 7 samples (10.29\%), all of which were suspected to be congenital anomalies.

Reliability or compliance tests were conducted using Bland Altman's limits of agreement analysis. Based on the analysis of the 68 samples, the average value, standard intersection, and range of conformity limit (95\% limit of agreement) can be obtained. Based on observer 1 and observer 2, ventricular and cranial indices showed no meaningful difference (bias) between observer 1 and observer 2 with a $p>$ value of 0.05 . Data from the interobserver test results of ventricular index and cranial index measurements obtained the maximum difference in ventricular index measurement in $95 \%$ limits of agreement. Band Altman between observers 1 and 2 respectively was -1.02 to 0.092 with an average difference of -0.005 and the p-value of 0.673 (Table 2)

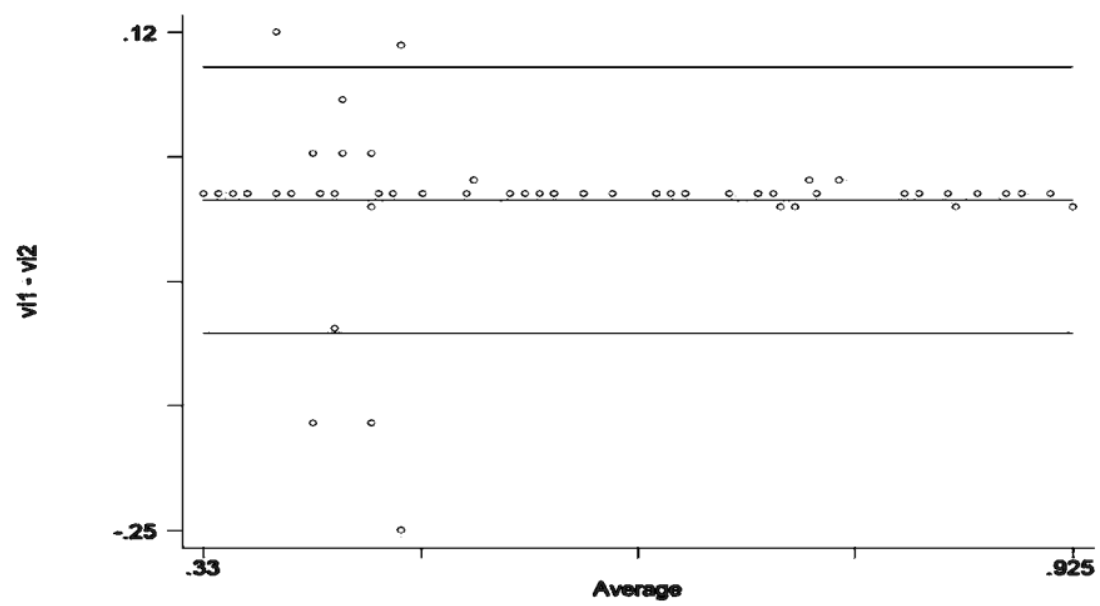

Figure 3. Bland Altman Plot Interobserver ventricular index measurement 


\section{mutiara \\ medika}

Table 2. Results of interobserver conformity test for ventricular index measurement

\begin{tabular}{lllll}
\hline Variable & $\mathrm{r}$ & $\begin{array}{l}\text { Average } \\
\text { Difference }\end{array}$ & $\begin{array}{l}\text { 95\% Limits of Agreement } \\
\text { (Bland\&Altman, 1986) }\end{array}$ & $\mathrm{p}$ \\
\hline Vi obs 1 & 0.958 & -0.005 & $-1.02-0.092$ & 0.673 \\
Vi obs 2 & & & & \\
\hline
\end{tabular}

While the suitability of cranial index measurement between observer 1 and observer 2 is -0.960 to 1.239 with an average difference of 0.139 and a p-value of 0.110 (Table 3). This analysis also shows that the distribution of measurement data with the highest conformity value is around the zero lines. Thus, the data with a high conformity value between the measurement by observer 1 and observer 2 plot is around the zero lines and can be narrowed (Figure 3 and Figure 4).

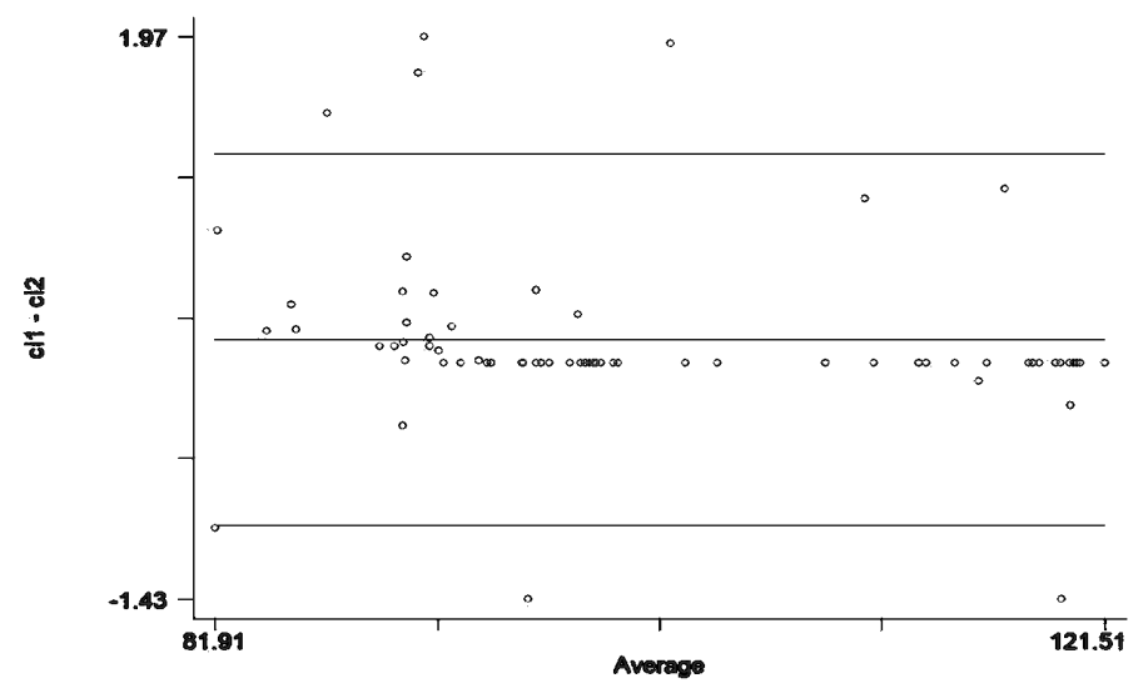

Figure 4: Bland Altman Plot Interobserver cranial index measurement

Table 3. Results of interobserver conformity test for cranial index measurement

\begin{tabular}{llllll}
\hline Variable & $\mathrm{r}$ & $\begin{array}{l}\text { Average } \\
\text { Difference }\end{array}$ & $\begin{array}{l}\text { 95\% Limits of Agreement } \\
\text { (Bland\&Altman, 1986) }\end{array}$ & $\mathrm{p}$ \\
\hline Ci obs 1 & 0.999 & 0.139 & $-0.960-1.239$ & 0.110 \\
Ci obs 2 & & & & \\
\hline
\end{tabular}

The correlation variables studied were ventricular index measurements with CT scans and cranial index measurements with scanograms. As the data distribution or data distribution was not normal with a $p$-value $<0.05$, the assessment was carried out using a non-parametric test of Spearman Rank correlation. Based on the measurement of the ventricular index, it was found that the correlation coefficient with Spearman's rho was 0.856 with a p-value $<0.001$ according to the scatter plot as in Figure 5.

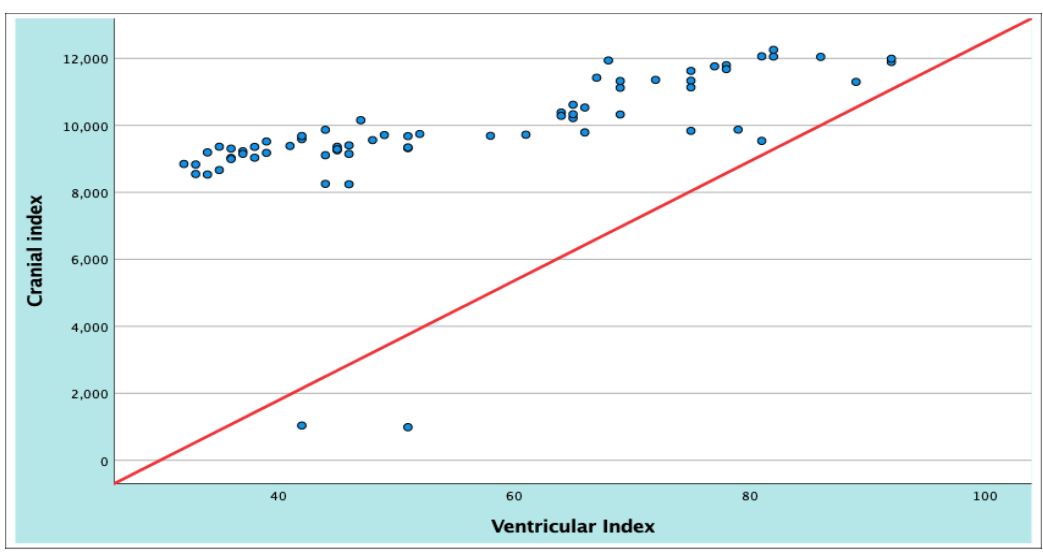

Figure 5. Scatter plot correlation between the ventricular index and cranial index 
To determine how much effect the ventricular index had on cranial index and the model of regression equation obtained from its constant value and coefficient of variable $B$, a simple linear regression test was conducted with ventricular index as variable $X$ and cranial index as variable $Y$. In Table 4, the intercept value is obtained, or constant is 2.973 with the value of coefficient $B 0.005, R^{2} 0.340$, and $\mathrm{P} 0.001$.

Table 4. Simple linear regression test results of the relationship between the ventricular index and cranial index

\begin{tabular}{llllll}
\hline Variable & $\begin{array}{l}\text { Intercept/ } \\
\text { constant }\end{array}$ & Coef B & $\begin{array}{l}95 \% \text { CI } \\
\text { Lower-Upper }\end{array}$ & P-value & $\mathrm{R}^{2}$ \\
\hline Ventricular index & 2.973 & 0.005 & $0.004-0.007$ & 0.001 & $34 \%$ \\
\hline
\end{tabular}

\section{DISCUSSION}

Hydrocephalus in children is a disease that can inhibit the growth and development of a child, thus affecting them in the future. Patients with hydrocephalus who get faster treatment at a younger age will have children with a normal level of intelligence. In radiology, the most important problem is detecting this hydrocephalus disease early to be treated quickly and adequately. ${ }^{7}$ Causes of hydrocephalus in children, in general, can be divided into two, prenatal and postnatal. Theoretically, hydrocephalus's pathophysiology occurs due to excessive production, increased fluid resistance, and increased venous sinus pressure in prenatal and postnatal aspects. ${ }^{8,9}$ Currently, radiological and imaging examinations that can detect hydrocephalus include skull radiography, sonography, CT-Scan, and MRI. Nowadays, ultrasound and CT scans are growing in detecting abnormalities early; thus, they become very useful input for clinicians, especially pediatricians and neurosurgeons. The CT-Scan examination can determine the presence of hydrocephalus, the type of hydrocephalus, detect the cause of the blockage and assess the degree of severity of hydrocephalus and can be performed quickly with a reduced radiation dose using an optimized protocol. ${ }^{10}$

Hydrocephalus is the most common cause of macrocrania in infants and children. The presence of enlargement of the head or macrocrania can be detected by examination of anteroposterior and lateral skull radiography with a widening of the sutures (especially coronal and lambdoid sutures), flattened sella turcica, thinning of the dorsum sella, increased convulsion markings, thinning of the tabula and enlarged calvarium on measurement. In infants and children under 2 years, the earliest sign of increased intracranial pressure is suture diastasis, especially coronal. Determination of cranial diameter in childhood is closely related to evaluating skull development in the clinical assessment of children and children's nerves. The size of the head of children can still change during the development period, especially the first year of life. ${ }^{11}$

The author attempts to improve the usefulness of skull plain radiographs by correlating ventricular index measurements with CT scans and cranial indexes with scanograms on CT scans; thus, it is expected that if there is a correlation, it can be used by colleagues in hospitals with limited facilities where patients need to re-control after surgery. It aims to determine the decrease in the degree of hydrocephalus using only anteriorposterior and lateral plain radiographs, especially in hospitals that do not have sophisticated equipment such as CT scans and are ineffective in the follow up of the skull development, considering the impossibility of determining the same positions and sizes of all structures involved for cranial measurement diameter. ${ }^{12}$

Based on the characteristic data in table 1 obtained from the calculation of the normality test in the age distribution, with a minimum age of zero months and the highest age of 120 months, gender characteristics were dominated by males than females. It aligns with the literature stating that male children were more commonly affected by hydrocephalus than female counterparts in all studies reporting data. ${ }^{13,14}$ Hydrocephalus was determined according to the triad of hydrocephalus proposed by Zhang et al., including the presence of widening of the anterior horn in a round or convex shape, dilatation of the posterior temporal horn, and the presence of periventricular hypodense. ${ }^{15}$ Based on the type of hydrocephalus listed in the table, the communicating type was much more than non-communicating hydrocephalus or the blockage above the IV ventricle. A study conducted by Harwood also found that $30 \%$ of non-communicating hydrocephalus subjects.

Based on the highest degree of hydrocephalus characteristics, severe cases were found by following under the findings of the most common types of communicants where there were various levels of the ventricle to the posterior horn to the presence macrocrania as a result of the presence of severe hydrocephalus. The hydrocephalus was caused by congenital abnormalities found in most of the samples that the authors identified, which was about 44 samples, among others, such as cases of Dandy-Walker Malformation. Furthermore, 11 samples of infection were found as the second cause, including ventriculitis, meningitis, and toxoplasmosis. The third most common cause of hydrocephalus was a tumor in as many as 6 
samples, among others, further caused by cases of medulloblastoma. Studies have demonstrated its presence in more than $50 \%$ of pediatric brain tumor cases at the time of diagnosis and as the second most common comorbidity at presentation. ${ }^{16,17}$

Moreover, there has never been a study that reviewed the relationship between the ventricular index and cranial index. Based on the correlation and regression test results, the measurements obtained showed a positive correlation value between the ventricular and cranial indices. The higher the ventricular index number is, the higher the cranial index value will be. After identifying the level of correlation between the two variables, it is also necessary to understand whether the ventricular index value has a significant effect on the cranial index value and can explain the cranial index value to the ventricular index with a linear equation.

Although imaging is frequently used to diagnose hydrocephalus, repeated head circumference measures cannot be adequately benchmarked in the long-term management of hydrocephalus. Head circumference should be adjusted based on an age-specific development curve, with special growth charts available for special populations with disturbances in growth, such as Down syndrome, Williams syndrome, prematurity, and achondroplasia..$^{18}$ Upward deviations in percentiles or intersections of percentile curves are signs that warrant additional inquiry; the patient's head circumferences were disproportionate to his or her weight or height, despite being within normal age limits. 19,20,21

This study was retrospective. The authors only explained the characteristics obtained based on the data listed in the PACS, which could be one of the limitations of this study. Therefore, the data did not include a pregnancy history, childbirth history, and nutritional factors, which might correlate with hydrocephalus.

\section{CONCLUSION}

Based on the result presented above, it can be concluded that there was a positive correlation between the measurement of the ventricular index and cranial index in hydrocephalus patients aged 0-12 years, illustrating that the larger the size of the ventricular index is, the wider the size of the cranial index will be.

\section{CONFLICT OF INTEREST}

The authors declare that there is no conflict of interest regarding the publication of this paper.

\section{REFERENCES}

1. Karimah D, Nurwati N, Basar GGK, Pengaruh Pemenuhan Kesehatan Anak Terhadap Perkembangan Anak, Prosiding Penelitian $\mathcal{E}$ Pengabdian Kepada MAsyarakat; 2015 2(1): 1-146. https://doi.org/10.24198/jppm.v2i1.13266

2. Toma AK, Papadopoulos MC, Stapleton S, Kitchen ND, Watkins LD. Systematic review of the outcome of shunt surgery in idiopathic normal-pressure hydrocephalus. Acta Neurochir (Wien). 2013 Oct;155(10):197780. https://doi.org/10.1007/s00701-013-1835-5

3. Satyanegara. Buku ajar Bedah Saraf Edisi IV.Jakarta : PT Gramedia Pustaka Utama; 2010. p.267-89.

4. Karakaś P, Koç F, Gülhal Bozkir M: Morphometric MRI Evaluation of corpus callosum and ventricle in normal adults. Neurolres 2011;33:1044-1049. https://doi.org/10.1179/1743132811Y.0000000030

5. Dhok A, Gupta P, Shaikh ST. Evaluation of the evan's and bicaudate index for the rural population in central India using computed tomography. Asian J Neurosurg 2020;15(1):94-7. https://doi.org/10.4103/ajns.AJNS 22319

6. Van Lindert EJ, Siepel FJ, Delye H, Ettema AM, Bergé SJ, Maal TJ, Borstlap WA. Validation of cephalic index measurement in scaphocephaly. Child's Nervous System.2013;29:1007-14. https://doi.org/10.1007/s00381-013-2059-y

7. Aristianti. Hidrosefalus. Cetakan 1 hal 1: Pustaka Pena Press Makassar;2012.

8. Espay AJ. Hydrocephalus [internet]; Medscape reference;1994 [update 2012 Sept 17;cited 2020 April 6]. Available from : https://eMedicine.medscape.com/article/11235286

9. Krishnamurthy, Satish, and Jie Li. "New concepts in the pathogenesis of hydrocephalus." Translational pediatrics vol. 3,3 (2014): 185-94. https://doi.org/110.3978/j.issn.2224-4336.2014.07.02.

10. Yabuuchi H, Kamitani T, Sagiyama K, Yamasaki Y, Matsuura Y, Hino T, et al. Clinical application of radiation dose reduction for head and neck CT. Eur J Radiol 2018;107:209-215. https://doi.org/10.1016/j.ejrad.2018.08.021 
11. Pereira IMR, Baros Filho AA, Alvares BR, Palomari ET, Nanni L. Radiological determination of cranial size and index by measurement of skull diameters in population of children in Brazil. Radiologi Bras. 2008;41 (4):229-34.

12. Swischuk LE. Radiologia do recém-nascido do lactente e da criança pequena. Rio de Janeiro: Guanabara Koogan; 2006. p.377-81

13. Hakami WS, Majeed-Saidan MA: The incidence and spectrum of central nervous system malformations in newborns over a decade (2001-2010) in the Central Region of Saudi Arabia. Saudi Med J.2011 Nov;32(11):1137-42.

14. Rashid QTA, Salat MS, Enam K, Kazim SF, Godil SS, Enam SA, et al. Time trends and age-related etiologies of pediatric hydrocephalus: results of a Groupwise analysis in a clinical cohort. Childs Nerv Syst.2012 Feb;28(2):221-7. https://doi.org/10.1007/s00381-011-1527-5

15. Zhang T, Zhou Y, Su G, et al. Hydrocephaly Analysis Supported by Computerized Tomography and Nuclear Magnetic Resonance. J Anal Methods Chem. 2019 Sep(2019):5872347. https://doi.org/10.1155/2019/5872347

16. Lanphear J, Sarnaik S. Presenting symptoms of pediatric brain tumors diagnosed in the emergency department. Pediatr Emerg Care. 2014;30(2):77-80. https://doi.org/10.1097/PEC.0000000000000074

17. Wong T-T, Liang M-L, Chen H-H, Chang F-C Hydrocephalus with brain tumors in children. Childs Nerv Syst. 2011;27(10):1723-1734. https://doi.org/10.1007/s00381-011-1523-9

18. American Academy of Pediatric. Microcephaly: McInerny TK, Adam HM, Campbell DE, DeWitt TG, Foy JM, Kamat DM, eds. American Academy of Pediatrics Textbook of Pediatric Care. American Academy of Pediatric (178);2017 [ cited 2021 June 12]. Available from https://pdfcoffee.com/american-academy-of-pediatricstextbook-of-pediatric-care-2nd-edition-pdf-free.html

19. Bergerat M, Heude B, Taine M, et al. Head circumference from birth to five years in France : New national reference chart and comparison to WHO standards. The Lancet regional health Europe.2021 June,volume 5,100114 [cited 2021 June 24]

20. Nicolaou L, Ahmed T, Bhutta ZA on behalf of the MALED Network Investigators, et al Factors associated with head circumference and indices of cognitive development in early childhood BMJ Global Health 2020;5:e003427. Available from : https://gh.bmj.com/content/5/10/e003427.citation-tools

21. Promoting optimal monitoring of child growth in Canada: using the new WHO growth charts. Executive summary. Ottawa, ON: Canadian Paediatric Society; 2014. Dietitians of Canada, Canadian Paediatric Society, the College of Family Physicians of Canada, Community Health Nurses of Canada. Available from : http://www.cps.ca/tools-outils/who-growth-charts 